\title{
RETRACTED ARTICLE: Structural Studies in Cryolite-Alumina Melts Investigated by Molecular Dynamics Simulations and High-Temperature NMR Data
}

\author{
MOUHAMADOU A. DIOP, SOKHNA A. BOUSSO, TAO WENJU, and LIU AIMIN
}

https://doi.org/10.1007/s11663-021-02223-5

(C) The Minerals, Metals \& Materials Society and ASM International 2021

THE corresponding author has retracted this article because following publication, the authors became aware that all figures and tables included in this paper have been previously published in a thesis by a different author [1]; Figs. 6 and 8 were also previously published in another article by the author of the thesis [2]. In addition, author S.A. Bousso has confirmed that they were not affiliated with Université Pierre \& Marie Curie at the time of submission and publication.

All authors agree to this retraction. The online version of this article contains the full text of the retracted article as Supplementary Information.

\section{ELECTRONIC SUPPLEMENTARY MATERIAL}

The online version of this article (https://doi.org/10.10 07/s11663-021-02223-5) contains supplementary material, which is available to authorized users.

\section{REFERENCES}

1. K. Machado. Chimie des Bains pour l'Electrolyse de l'Aluminium : Étude RMN Haute Température et Modélisation. Autre. Université d'Orléans, 2017. Français. ffNNT : 2017ORLE2054.

2. K. Machado, D. Zanghi, V. Sarou-Kanian, S. Cadars, M. Burbano, M. Salanne, C. Bessada, Study of NaF-AlF3 Melts by Coupling Molecular Dynamics, Density Functional Theory, and NMR Measurements, J. Phys. Chem. C. 121 (2017) 10289-10297. https://doi.org/10.1021/acs.jpcc.7b01530.
MOUHAMADOU A. DIOP, TAO WENJU, and LIU AIMIN are with the School of Metallurgy, Northeastern University, Wenhua Road, Shenyang, 110819, P.R. China. Contact e-mail: diop@smm.neu.edu.cn SOKHNA A. BOUSSO is with the Universite Pierre \& Marie Curie, Laboratoire de Hautes Énergies, Jussieu, Cedex 04, 75004, Paris, France.

Manuscript submitted December 12, 2020; accepted May 12, 2021.

Article published online June 28, 2021. 